\title{
Increased low-grade inflammation and plasminogen-activator inhibitor-1 level in non-dippers with sleep apnea syndrome
}

\author{
Joji Ishikawa ${ }^{1,2}$, Satoshi Hoshide ${ }^{1}$, Kazuo Eguchi ${ }^{1}$, Shizukiyo Ishikawa ${ }^{3}$, Thomas G \\ Pickering $^{3}$, Kazuyuki Shimada ${ }^{1}$, and Kazuomi Kario ${ }^{1}$ \\ ${ }^{1}$ Division of Cardiovascular Medicine, Department of Medicine, Jichi Medical University School of \\ Medicine, Tochigi, Japan \\ ${ }^{2}$ Division of General Medicine, Department of Medicine, Center for Behavioral Cardiovascular \\ Health, Columbia University Medical Center, New York, USA \\ ${ }^{3}$ Division of Community and Family medicine, Jichi Medical University School of Medicine, \\ Tochigi, Japan
}

\begin{abstract}
Objective-Patients with sleep apnea syndrome (SAS) have an increased risk of cardiovascular events and frequently show a non-dipper pattern (blunted nocturnal decline $<10 \%$ ) of systolic blood pressure (BP). We investigated neurohumoral activation and risk factors in relation to nocturnal BP dipping pattern and SAS.
\end{abstract}

Methods-We conducted sleep polysomnography and ambulatory BP monitoring, and measured high-sensitivity C-reactive protein (hsCRP), tissue-type plasminogen activator inhibitor-1 (PAI-1), and neurohumoral factors in 121 outpatients with suspected SAS, who were classified in 4 groups depending on the presence or absence of dipping/non-dipping and SAS.

Results-Non-dippers with SAS had higher hsCRP (overall P<0.001), PAI-1 (overall $\mathrm{P}=0.004$ ), and aldosterone levels (overall $\mathrm{P}=0.010$ ) than any of the other 3 groups. After adjustment for significant covariates such as age, sex, body mass index, waist circumference, smoking, alcohol drinking, aspirin use, presence of DM, and insulin, non-dippers with SAS still had a higher hsCRP level than non-dippers without SAS (geometric mean: 1.47 vs. $0.37 \mathrm{mg} / \mathrm{L}, \mathrm{P}=0.001$ ). In multiple linear regression analysis controlling for confounding factors that related with SAS, hsCRP was significantly correlated with $3 \%$ oxygen desaturation index $(\mathrm{P}=0.047)$. PAI-1 was also highest in the non-dippers with SAS, but this was not independent of obesity. PAI-1 was correlated with insulin ( $\mathrm{r}=0.32, \mathrm{P}=0.002)$ and hsCRP levels $(\mathrm{r}=0.26, \mathrm{P}=0.005)$.

Conclusion-Non-dipper status was associated with an increased hsCRP in patients who also had SAS, but not in those who did not, and hsCRP was closely affected by the desaturation level. PAI-1 is also increased in non-dippers with SAS, and is related to insulin and hsCRP.

\section{Keywords}

sleep apnea syndrome; non-dipper; high-sensitivity C-reactive protein; plasminogen activator inhibitor-1

\footnotetext{
Address correspondence to: Joji Ishikawa, MD, PhD, Division of Cardiovascular Medicine, Department of Medicine, Jichi Medical University, School of Medicine 3311-1, Yakushiji, Shimotsuke, Tochigi, 329-0498, JAPAN, Tel: +81-285-58-7344; FAX: +81-285-44-2132, george@jichi.ac.jp.

Disclosure: The first author is supported in part by Mitsubishi Tanabe Pharma Research Foundation grant.
} 


\section{Introduction}

Sleep apnea syndrome (SAS) is reported to be associated with an increased risk for atherosclerosis [1], prevalence [2] and incidence of hypertension [3], cardiovascular events [4,5], and sudden death during sleep [6]. Patients with SAS often have a blunted nocturnal blood pressure dip (non-dipper status) during 24-hour ambulatory blood pressure monitoring (ABPM) [7], and continuous positive airway pressure (CPAP) converts non-dippers to dippers [8].

Non-dippers are reported to have increased risk for left ventricular hypertrophy [9], silent cerebral infarcts [10], and cardiovascular mortality [11]. The non-dipper status may contribute to an increased risk for cardiovascular events in patients with SAS. However, there are no data about the differences in risk factors of cardiovascular events in patients classified according to dipper status and SAS.

High-sensitivity C-reactive protein (hsCRP), a marker of low-grade inflammation, is reported to be a marker of atherosclerosis [12], hypertensive target organ damage [13], and cardiovascular events [14]. The hsCRP level is also reported to be increased in patients with SAS [15,16], but there are no data that show differences of hsCRP between non-dippers with SAS and non-dippers without SAS.

Additionally, plasminogen-activator inhibitor-1 (PAI-1), a marker of fibrinolysis, is thought to be a risk factor for cardiovascular events [17]. PAI-1 gene transcription was reported to be stimulated by hypoxia in an experimental model [18]. However, the differences in PAI-1 level among dippers and non-dippers with or without SAS have remained unclear, and the relationships of PAI-1 level with apnea-hypopnea index (AHI), hypoxia, obesity, and other humoral factors are also unknown.

The purpose of this study was to evaluate the relationship of hsCRP and PAI-1 in patients classified according to dipper status and SAS, and evaluate the factors in SAS that are associated with hsCRP and PAI-1 level.

\section{Methods}

\section{Patients}

We evaluated 121 patients who underwent polysomnography (PSG) because of suspected sleep apnea syndrome (such as symptoms of daytime sleepiness or snoring), and who were conducted ABPM and blood examinations in this study. The patients enrolled in this study were selected from 134 consecutive patients who underwent PSG for diagnosis of SAS in our hospital between September 2001 and October 2004, after excluding 13 patients because of incomplete data.

Clinic BP was measured as the average of 2 consecutive measurements made after patients had rested for at least 5 minutes in a seated position on the day of ABPM measurement. Diabetes was diagnosed as fasting glucose $\geq 7.0 \mathrm{mmol} / \mathrm{L}(126 \mathrm{mg} / \mathrm{dl})$, a random serum glucose $\geq 11.1 \mathrm{mmol} / \mathrm{l}$ (200 mg/dl) and/or anti-diabetic drugs use. Hyperlipidemia was defined as a total cholesterol level $\geq 5.7 \mathrm{mmol} / \mathrm{L}(220 \mathrm{mg} / \mathrm{dL})$, triglyceride level $\geq 1.7 \mathrm{mmol} /$ $1(150 \mathrm{mg} / \mathrm{dl})$ and/or oral lipid-lowering agent use. Smokers were defined as current smokers. Patients who were drinking alcohol every day were defined as alcohol drinkers. Body mass index (BMI) was calculated as weight (in kilograms)/[height (in meters)] ${ }^{2}$.

The institutional review board of Jichi Medical University approved this study. 


\section{Polysomnography}

Overnight fully diagnostic sleep polysomnography was performed using a P series model 4 Plus (Compumedics Ltd, Australia) or E series/PSG (Compumedics Ltd, Australia), that recorded the following parameters: ECG, central and occipital electroencephalogram, bilateral electrooculogram, submental electomyogram, nasal airflow, using a nasal cannula and pressure transducer, naso-oral airflow, using a thermistor (P series) or thermo couple (E series), and respiratory effort using chest and abdominal piezoelectric belts. Oxyhemoglobin saturation $\left(\mathrm{SpO}_{2}\right)$ was monitored using a pulse oximeter (Probe Nonin Oximeter 8000J). Sleep staging was scored according to the criteria of Kales and Rechtschaffen [19]. Apneas were defined as decrements in airflow $>90 \%$ from baseline for a period $>10$ seconds, and hypopneas were defined as decrements in airflow $>50 \%$ but $<90 \%$ from baseline for a period $>10$ seconds [20]. The number of apneas and hypopneas per hour of sleep were calculated to obtain the AHI. SAS was defined as AHI>15 according to a previous report [21]. Respiratory events were judged primarily from the nasal cannula-pressure transducer.

\section{ABPM}

ABPM was measured using a validated machine: TM-2425 (A\&D Co., Japan). Measurements were performed at 30-min intervals for 24 hours on a weekday just before or after the PSG. Nighttime parameters (BP and pulse rate) were defined by the averages from the time after going to bed to the time before waking up, and daytime parameters were defined by the averages from the time after awakening to the time before going to bed. The patients reported the time of awakening and going to bed. The night/day ratios of systolic blood pressure were calculated. Nocturnal BP fall was calculated as 1 minus the night/day ratio of systolic blood pressure and expressed as a percentage. Patients were classified into the following 2 dipping groups on the basis of the nocturnal BP fall: dippers, with a fall larger than 10\%; and non-dippers, with a fall less than $10 \%$. SpO2 was also measured during ABPM. The oxygen desaturation index (ODI) was defined as the total number of episodes of oxyhemoglobin desaturation $>3 \%$, divided by the total sleep time.

\section{Blood examination}

Blood samples were drawn from the antecubital vein in the fasting state in the morning after the diagnostic PSG. All blood samples were measured in the same laboratory (SRL, Inc., Tokyo, Japan). Serum hsCRP level was measured by nephelometry (NA Latex CRP kit, Dade Behring, Tokyo, Japan). The plasma levels of PAI-1 were determined using commercially available latex photometric immunoassay kits for PAI-1 (Mitsubishi Kagaku Latoron, Tokyo, Japan). Blood for measurement of plasma renin activity (PRA) and aldosterone was drawn into tubes containing EDTA. PRA was measured by radioimmunoassay (SRL Inc., Tokyo, Japan). Angiotensin II measurements were made by radioimmunoassay (SRL Inc., Tokyo, Japan). Aldosterone concentrations were measured with the use of a commercially available radioimmunoassay (SRL Inc., Tokyo, Japan). Catecholamine concentrations were measured by high performance liquid chromatography (Tosoh Corporation, Tokyo, Japan).

\section{Statistical analysis}

Data are shown as the mean \pm S.D. The values of hsCRP had a skewed distribution and the analyses of these values were performed for the log-transformed values. One-way analysis of variance (ANOVA) was performed to detect differences among the patients in the 4 groups, and Tukey's honestly significant differences test was used for multiple pairwise comparisons of means among the groups. Analysis of covariance (ANCOVA) was performed to detect differences among the groups after adjustment for confounding factors, and the Bonferroni test was used for multiple pairwise comparisons. Correlations between 
AHI and BMI, hsCRP level, aldosterone level and PAI-1 level were analyzed using Pearson's test. HsCRP, aldosterone, and PAI-1 levels were correlated with some other variables; therefore, analysis of covariance and partial correlation coefficients were examined to rule out their effects on these parameters in multiple linear regression analysis. The computer software SPSS version 11.0 (SPSS Inc., Chicago, USA) was used for the analyses and probability $<0.05$ was considered statistically significant.

\section{Results \\ Patients}

The mean age of the patients was $58.1 \pm 15.1$ years old; there were 90 men and 31 women, and the mean BMI was $26.3 \pm 4.4 \mathrm{~kg} / \mathrm{m}^{2}$. There were 25 non-dippers with SAS, 44 dippers with SAS, 24 non-dippers without SAS, and 28 dippers without SAS.

\section{Characteristics of patients classified according to the presence or absence of SAS and dipping status}

The characteristics of patients classified according to the presence or absence of SAS and dipping status are shown in Table 1 . The age was younger and the percentage of men was higher in the patients with SAS than in those without SAS. The percentage of patients who were taking antihypertensive medications was $47.1 \%$ (calcium channel blockers $30 \%$, angiotensin II receptor blockers $15 \%$, angiotensin-converting enzyme inhibitors $6.7 \%$, diuretics $2.5 \%$, alpha-blockers $8.3 \%$, and beta-blockers $7.5 \%$ ). The percentages of patients who were taking aspirin, statins, and oral antidiabetic drugs were $17.4 \%, 5.0 \%$, and $2.5 \%$, respectively. As shown in Table 1, there were no significant differences in the use of medications among the 4 groups.

\section{Polysomnogram parameters, BPs, and neurohumoral factors}

Differences in polysomnographic parameters in the 4 groups of patients are shown in Table 2. Non-dippers with SAS had the most severe AHI and 3\% ODI; however, non-dipping status did not closely follow the severity of SAS. There were no BP differences among the groups. The neurohumoral factors in the 4 groups of patients are shown in Table 3 . Nondippers with SAS had significantly higher hsCRP levels than the other 3 groups. Even after adjustment for significant confounding factors including age, sex, BMI, waist circumference, smoking, drinking, aspirin use, presence of DM, and insulin level, the nondippers with SAS still had significantly higher hsCRP than the non-dippers without SAS, and than the dippers with SAS (Figure 1). Although non-dippers with SAS also had the highest PAI-1 level, differences from the other groups were not significant after adjustment for $\mathrm{BMI}(\mathrm{P}=0.22)$.

Patients who were taking antihypertensive medication had lower aldosterone levels ( $99.8 \pm 38.4$ vs. $84.2 \pm 36.4 \mathrm{pg} / \mathrm{ml}, \mathrm{P}=0.023)$, higher adrenaline ( $14.0 \pm 11.0$ vs. $18.3 \pm 12.3 \mathrm{pg} /$ $\mathrm{ml}, \mathrm{P}=0.043)$ and higher noradrenaline $(285 \pm 153$ vs. $367 \pm 197 \mathrm{pg} / \mathrm{ml}, \mathrm{P}=0.013)$ than those without antihypertensive medication. There were no statistical differences in hsCRP, aldosterone, and PAI-1 levels between users of different antihypertensive drug classes (such as calcium channel blockers, angiotensin II receptor blockers, angiotensin converting enzyme inhibitors, alpha-blockers, beta-blockers) and non-users. Patients who were taking diuretics $(\mathrm{N}=3)$ had higher hsCRP level than those who were not $(\mathrm{P}=0.019)$. There were 6 patients with resistant hypertension (number of antihypertensive drug $\geq 3$ and $\mathrm{CBP} \geq 140 / 90 \mathrm{mmHg}$ ), and had a significantly higher AHI than those without resistant hypertension ( $42.1 \pm 20.9$ vs. $23.2 \pm 20.1 \mathrm{event} / \mathrm{hr}, \mathrm{P}=0.027)$. But, there were no significant differences in hsCRP $(\mathrm{P}=0.91)$ and PAI-1 $(\mathrm{P}=0.20)$ between the patients with and without resistance hypertension. 


\section{Correlations of neurohumoral factors and factors related to SAS}

$\log _{10}$ hsCRP level was correlated with BMI ( $\left.r=0.34, \mathrm{P}<0.001\right)$, AHI $(\mathrm{r}=0.38, \mathrm{P}<0.001), 3 \%$ ODI ( $\mathrm{r}=0.42, \mathrm{P}<0.001)$, insulin $(\mathrm{r}=0.20, \mathrm{P}=0.031)$, and aldosterone $(\mathrm{r}=0.18, \mathrm{P}=0.048)$. After controlling for these confounding factors in multiple regression analysis, $\log _{10}$ hsCRP level was correlated with 3\% ODI (beta $=0.25, \mathrm{P}=0.047$ ) (Table 4). Even after we added significant confounding factors including age, sex, smoking, alcohol drinking, aspirin use, and diabetes to the model, $\log _{10}$ hsCRP level had a tendency to be correlated with $3 \%$ ODI (beta $=0.21, \mathrm{P}=0.089$ ).

PAI-1 level was correlated with BMI ( $\mathrm{r}=0.38, \mathrm{P}<0.001)$, AHI ( $\mathrm{r}=0.31, \mathrm{P}=0.001), 3 \%$ ODI $(\mathrm{r}=0.31, \mathrm{P}<0.001)$, arousal index $(\mathrm{r}=0.18, \mathrm{P}=0.043)$, insulin $(\mathrm{r}=0.44, \mathrm{P}<0.001)$, aldosterone $(\mathrm{r}=0.17, \mathrm{P}=0.065)$, and $\log _{10}$ hsCRP levels $(\mathrm{r}=0.38, \mathrm{P}<0.001)$. After controlling for these confounding factors in multiple regression analysis, PAI-1 was correlated with insulin (beta=0.32, $\mathrm{P}=0.002$ ) and $\log _{10}$ hsCRP (beta $=0.26, \mathrm{P}=0.005$ ) (Table 4). Even after we added significant confounding factors including age, sex, smoking, alcohol drinking, aspirin use, and diabetes to the model, PAI- 1 was still correlated with insulin $(r=0.37, \mathrm{P}<0.001)$ and $\log _{10}$ hsCRP level ( $\left.r=0.28, \mathrm{P}=0.002\right)$.

Aldosterone level was correlated with BMI ( $\mathrm{r}=0.19, \mathrm{P}=0.034)$, AHI ( $\mathrm{r}=0.26, \mathrm{P}=0.004)$, arousal index ( $\mathrm{r}=0.18, \mathrm{P}=0.045)$, Insulin ( $\mathrm{r}=0.29, \mathrm{P}=0.001)$, and $\log _{10} \mathrm{hsCRP}$ levels $(\mathrm{r}=0.18$, $\mathrm{P}=0.048)$, and was weakly correlated with $3 \%$ ODI $(\mathrm{r}=0.16, \mathrm{P}=0.078)$. After controlling for these confounding factors related to SAS in multiple regression analysis, aldosterone was correlated with insulin (beta $=0.23, \mathrm{P}=0.039$ ) (Table 4), and this correlation remained significant (beta $=0.26, \mathrm{P}=0.022$ ) even after we added other significant confounding factors including age, sex, smoking, alcohol drinking, aspirin use, and diabetes to the model.

\section{Discussion}

Non-dippers with SAS had increased hsCRP independently of significant confounding factors including BMI, while non-dippers without SAS did not. This indicates that nondipper status itself was not associated with increased hsCRP. In contrast, the presence of SAS (AHI>15) was associated with increased hsCRP (in relation to the desaturation level) independently of dipping status. PAI-1 was also increased in non-dippers with SAS, but this was not independent of obesity, although it was related to both insulin and hsCRP.

Increased risks of non-dippers for cardiovascular events may be partly explained by background diseases that lead to the non-dipper state. Thus in a population-based study, Bjorklund et al. [22] reported that the majority of non-dipping men did not have an increased cardiovascular risk, although non-dippers who had diabetes did. There may be 2 types of non-dippers (with and without other risk factors such as SAS and/or diabetes), and the risks of non-dipper status may be partly explained by the subjects' backgrounds that lead to non-dipper status. Verdecchia, et al. [23] reported that non-dippers with sleep deprivation induced by cuff inflations during nighttime ABPM did not have increased cardiovascular mortality.

Some of the mechanisms by which SAS may increase blood pressure include the reninangiotensin-aldosterone system [24,25], sympathetic nerve activation [26], endothelial dysfunction [27], endothelin [28], and oxidative stress [29]. These parameters also have been reported to be correlated with hsCRP levels [30-33]. It has been reported that hsCRP is increased with the severity of SAS independently of BMI [16], and that treatment with nasal continuous positive airway pressure lowers hsCRP in association with reduction of AHI [34]. In our present study, hsCRP level was more significantly correlated with 3\% ODI than with AHI. On the other hand, Norman et al.[35] reported that supplementing nocturnal 
oxygen supply did not reduce the nighttime blood pressures in patients with obstructed SAS, but that continuous positive airway pressure therapy did reduce it. Mechanisms that increase hsCRP (e.g. desaturation) and cause non-dipping status (e.g. impaired respiration) may be more important in non-dippers with SAS.

The pathophysiological mechanisms that increase PAI-1 are likely to be complicated in patients with SAS. PAI-1 is reported to be increased by various factors (i.e., obesity and/or metabolic syndrome [36], and hypoxia [37]). Experimental studies have demonstrated that production of PAI-1 is increased with hypoxia [38]. In the present study, the PAI-1 level was increased in non-dippers with SAS, and this relationship was partly accounted for by the insulin level and hsCRP. von Kanel et al. [39] reported that measures reflecting apnea severity (higher AHI and more of the nighttime spent with $\mathrm{SpO}_{2}<90 \%$ ), and sleep efficiency (percentage of sleep duration divided by duration of time in bed) were related to PAI-1, but insulin and hsCRP were not measured in their analysis. In the present study, PAI-1 levels were more significantly correlated with insulin and hsCRP than hypoxia or AHI, and the increased level of PAI-1 in non-dippers with SAS might be induced by inflammation associated with desaturation.

\section{Study limitations}

There were some subjects in the present study who were taking antihypertensive medications, which might have affected some of the neurohumoral factors that we measured, although there were no statistical differences in medication use among the 4 groups of patients. The patients who were taking antihypertensive medication had lower aldosterone levels than those who were not. However, even in an analysis of only patients who were taking no antihypertensive medication, aldosterone in non-dippers with SAS tended to be higher than in non-dippers without SAS (data not shown). Additionally, 6 patients were taking statins and which is reported to decrease hsCRP. In the present study, patients who were taking stains had lower hsCRP; however, even when we analyzed our data excluding for patients who were taking statins, the results were almost similar (data not shown).

\section{Conclusion}

Non-dipper status on its own was not associated with an increased level of hsCRP, whereas SAS was. There was also an additive effect such that the highest levels were seen in patients with SAS who were also non-dippers. HsCRP was closely affected by the nocturnal desaturation level. PAI-1 is also increased in non-dippers with SAS, and is related to increases of insulin and hsCRP.

\section{Acknowledgments}

Financial support: The study was supported in part by NHLBI grants PO1 HL 47540 and R24 HL76857

\section{References}

1. Drager LF, Bortolotto LA, Lorenzi MC, Figueiredo AC, Krieger EM, Lorenzi-Filho G. Early signs of atherosclerosis in obstructive sleep apnea. Am J Respir Crit Care Med. 2005; 172:613-618. [PubMed: 15901608]

2. Nieto FJ, Young TB, Lind BK, Shahar E, Samet JM, Redline S, D'Agostino RB, Newman AB, Lebowitz MD, Pickering TG. for the Sleep Heart Health Study. Association of sleep-disordered breathing, sleep apnea, and hypertension in a large community-based study. JAMA. 2000;

283:1829-1836. [PubMed: 10770144] 
3. Peppard PE, Young T, Palta M, Skatrud J. Prospective study of the association between sleepdisordered breathing and hypertension. N Engl J Med. 2000; 342:1378-1384. [PubMed: 10805822]

4. Yaggi HK, Concato J, Kernan WN, Lichtman JH, Brass LM, Mohsenin V. Obstructive sleep apnea as a risk factor for stroke and death. N Engl J Med. 2005; 353:2034-2041. [PubMed: 16282178]

5. Marin JM, Carrizo SJ, Vicente E, Agusti AG. Long-term cardiovascular outcomes in men with obstructive sleep apnoea-hypopnoea with or without treatment with continuous positive airway pressure: An observational study. Lancet. 2005; 365:1046-1053. [PubMed: 15781100]

6. Gami AS, Howard DE, Olson EJ, Somers VK. Day-night pattern of sudden death in obstructive sleep apnea. N Engl J Med. 2005; 352:1206-1214. [PubMed: 15788497]

7. Portaluppi F, Provini F, Cortelli P, Plazzi G, Bertozzi N, Manfredini R, Fersini C, Lugaresi E. Undiagnosed sleep-disordered breathing among male nondippers with essential hypertension. J Hypertens. 1997; 15:1227-1233. [PubMed: 9383171]

8. Akashiba T, Minemura H, Yamamoto H, Kosaka N, Saito O, Horie T. Nasal continuous positive airway pressure changes blood pressure "Non-dippers" To "Dippers" In patients with obstructive sleep apnea. Sleep. 1999; 22:849-853. [PubMed: 10566903]

9. Hoshide S, Kario K, Hoshide Y, Umeda Y, Hashimoto T, Kunii O, Ojima T, Shimada K. Associations between nondipping of nocturnal blood pressure decrease and cardiovascular target organ damage in strictly selected community-dwelling normotensives. Am J Hypertens. 2003; 16:434-438. [PubMed: 12799090]

10. Shimada K, Kawamoto A, Matsubayashi K, Nishinaga M, Kimura S, Ozawa T. Diurnal blood pressure variations and silent cerebrovascular damage in elderly patients with hypertension. $\mathbf{J}$ Hypertens. 1992; 10:875-878. [PubMed: 1325522]

11. Ohkubo T, Hozawa A, Yamaguchi J, Kikuya M, Ohmori K, Michimata M, Matsubara M, Hashimoto J, Hoshi H, Araki T, Tsuji I, Satoh H, Hisamichi S, Imai Y. Prognostic significance of the nocturnal decline in blood pressure in individuals with and without high 24-h blood pressure: The Ohasama study. J Hypertens. 2002; 20:2183-2189. [PubMed: 12409956]

12. Ross R. Atherosclerosis -- an inflammatory disease. N Engl J Med. 1999; 340:115-126. [PubMed: 9887164]

13. Ishikawa J, Tamura Y, Hoshide S, Eguchi K, Ishikawa S, Shimada K, Kario K. Low-grade inflammation is a risk factor for clinical stroke events in addition to silent cerebral infarcts in japanese older hypertensives. The Jichi Medical School ABPM study, wave 1. Stroke. 2007; 38:911-917. [PubMed: 17272770]

14. Ridker PM, Rifai N, Rose L, Buring JE, Cook NR. Comparison of C-reactive protein and lowdensity lipoprotein cholesterol levels in the prediction of first cardiovascular events. N Engl J Med. 2002; 347:1557-1565. [PubMed: 12432042]

15. Larkin EK, Rosen CL, Kirchner HL, Storfer-Isser A, Emancipator JL, Johnson NL, Zambito AMV, Tracy RP, Jenny NS, Redline S. Variation of C-reactive protein levels in adolescents: Association with sleep-disordered breathing and sleep duration. Circulation. 2005; 111:1978-1984. [PubMed: 15837952]

16. Shamsuzzaman ASM, Winnicki M, Lanfranchi P, Wolk R, Kara T, Accurso V, Somers VK. Elevated c-reactive protein in patients with obstructive sleep apnea. Circulation. 2002; 105:24622464. [PubMed: 12034649]

17. Folsom AR, Aleksic N, Park E, Salomaa V, Juneja H, Wu KK. Prospective study of fibrinolytic factors and incident coronary heart disease: The atherosclerosis risk in communities (ARIC) study. Arterioscler Thromb Vasc Biol. 2001; 21:611-617. [PubMed: 11304480]

18. Uchiyama T, Kurabayashi M, Ohyama Y, Utsugi T, Akuzawa N, Sato M, Tomono S, Kawazu S, Nagai R. Hypoxia induces transcription of the plasminogen activator inhibitor-1 gene through genistein-sensitive tyrosine kinase pathways in vascular endothelial cells. Arterioscler Thromb Vasc Biol. 2000; 20:1155-1161. [PubMed: 10764687]

19. Rechtschaffen, A.; Kales, A. A manual of standardized terminology and scoring system for sleep stages of human subjects. Brain Information Service/Brain Research Institute, University of California at Los Angeles; Los Angeles, CA: 1968. 
20. EEG arousals: Scoring rules and examples: A preliminary report from the Sleep Disorders Atlas Task Force of the American Sleep Disorders Association. Sleep. 1992; 15:173-184. [PubMed: 11032543]

21. Young T, Palta M, Dempsey J, Skatrud J, Weber S, Badr S. The occurrence of sleep-disordered breathing among middle-aged adults. N Engl J Med. 1993; 328:1230-1235. [PubMed: 8464434]

22. Bjorklund K, Lind L, Andren B, Lithell H. The majority of nondipping men do not have increased cardiovascular risk: A population-based study. J Hypertens. 2002; 20:1501-1506. [PubMed: 12172310]

23. Verdecchia P, Angeli F, Borgioni C, Gattobigio R, Reboldi G. Ambulatory blood pressure and cardiovascular outcome in relation to perceived sleep deprivation. Hypertension. 2007; 49:777783. [PubMed: 17261645]

24. Moller DS, Lind P, Strunge B, Pedersen EB. Abnormal vasoactive hormones and 24-hour blood pressure in obstructive sleep apnea. Am J Hypertens. 2003; 16:274-280. [PubMed: 12670743]

25. Calhoun DA, Nishizaka MK, Zaman MA, Harding SM. Aldosterone excretion among subjects with resistant hypertension and symptoms of sleep apnea. Chest. 2004; 125:112-117. [PubMed: 14718429]

26. Narkiewicz K, van de Borne PJH, Cooley RL, Dyken ME, Somers VK. Sympathetic activity in obese subjects with and without obstructive sleep apnea. Circulation. 1998; 98:772-776. [PubMed: 9727547]

27. Ip MSM, Tse H-F, Lam B, Tsang KWT, Lam W-K. Endothelial function in obstructive sleep apnea and response to treatment. Am J Respir Crit Care Med. 2004; 169:348-353. [PubMed: 14551167]

28. Allahdadi KJ, Walker BR, Kanagy NL. Augmented endothelin vasoconstriction in intermittent hypoxia-induced hypertension. Hypertension. 2005; 45:705-709. [PubMed: 15738350]

29. Yamauchi M, Nakano H, Maekawa J, Okamoto Y, Ohnishi Y, Suzuki T, Kimura H. Oxidative stress in obstructive sleep apnea. Chest. 2005; 127:1674-1679. [PubMed: 15888845]

30. Ridker PM, Danielson E, Rifai N, Glynn RJ. for the Val-MARC Investigators. Valsartan, blood pressure reduction, and C-reactive protein: Primary report of the val-marc trial. Hypertension. 2006; 48:73-79. [PubMed: 16714425]

31. Aso Y, Wakabayashi S, Nakano T, Yamamoto R, Takebayashi K, Inukai T. High serum highsensitivity C-reactive protein concentrations are associated with relative cardiac sympathetic overactivity during the early morning period in type 2 diabetic patients with metabolic syndrome. Metabolism. 2006; 55:1014-1021. [PubMed: 16839835]

32. Cottone S, Mule G, Nardi E, Vadala A, Lorito MC, Guarneri M, Arsena R, Palermo A, Cerasola G. $\mathrm{C}$-reactive protein and intercellular adhesion molecule-1 are stronger predictors of oxidant stress than blood pressure in established hypertension. J Hypertens. 2007; 25:423-428. [PubMed: 17211250]

33. Wang T-D, Chen W-J, Cheng W-C, Lin J-W, Chen M-F, Lee Y-T. Relation of improvement in endothelium-dependent flow-mediated vasodilation after rosiglitazone to changes in asymmetric dimethylarginine, endothelin-1, and C-reactive protein in nondiabetic patients with the metabolic syndrome. Am J Cardiol. 2006; 98:1057-1062. [PubMed: 17027571]

34. Yokoe T, Minoguchi K, Matsuo H, Oda N, Minoguchi H, Yoshino G, Hirano T, Adachi M. Elevated levels of C-reactive protein and interleukin-6 in patients with obstructive sleep apnea syndrome are decreased by nasal continuous positive airway pressure. Circulation. 2003; 107:1129-1134. [PubMed: 12615790]

35. Norman D, Loredo JS, Nelesen RA, Ancoli-Israel S, Mills PJ, Ziegler MG, Dimsdale JE. Effects of continuous positive airway pressure versus supplemental oxygen on 24-hour ambulatory blood pressure. Hypertension. 2006; 47:840-845. [PubMed: 16585412]

36. Alessi M-C, Juhan-Vague I. PAI-1 and the metabolic syndrome: Links, causes, and consequences. Arterioscler Thromb Vasc Biol. 2006; 26:2200-2207. [PubMed: 16931789]

37. Pinsky DJ, Liao H, Lawson CA, Yan S-F, Chen J, Carmeliet P, Loskutoff DJ, Stern DM. Coordinated induction of plasminogen activator inhibitor-1 (PAI-1) and inhibition of plasminogen activator gene expression by hypoxia promotes pulmonary vascular fibrin deposition. J Clin Invest. 1998; 102:919-928. [PubMed: 9727060] 
38. Yan S-F, Mackman N, Kisiel W, Stern DM, Pinsky DJ. Hypoxia/hypoxemia-induced activation of the procoagulant pathways and the pathogenesis of ischemia-associated thrombosis. Arterioscler Thromb Vasc Biol. 1999; 19:2029-2035. [PubMed: 10479642]

39. von Kanel R, Loredo JS, Ancoli-Israel S, Mills PJ, Natarajan L, Dimsdale JE. Association between polysomnographic measures of disrupted sleep and prothrombotic factors. Chest. 2007; 131:733739. [PubMed: 17356087] 


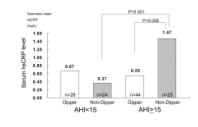

Figure 1. High-sensitivity C-reactive protein level in patients according to dipper status and sleep apnea syndrome

AHI indicates apnea-hypopnea index; hsCRP, high-sensitivity C-reactive protein. Data are shown as geometric mean. Overall $\mathrm{P}$ values were calculated by ANCOVA after adjustment for significant covariates such as age, sex, body mass index, waist circumference, smoking, drinking, aspirin use, presence of diabetes, and insulin level. Intergroup differences were calculated by the Bonferroni test. Probability 0.05 was considered statistically significant. 


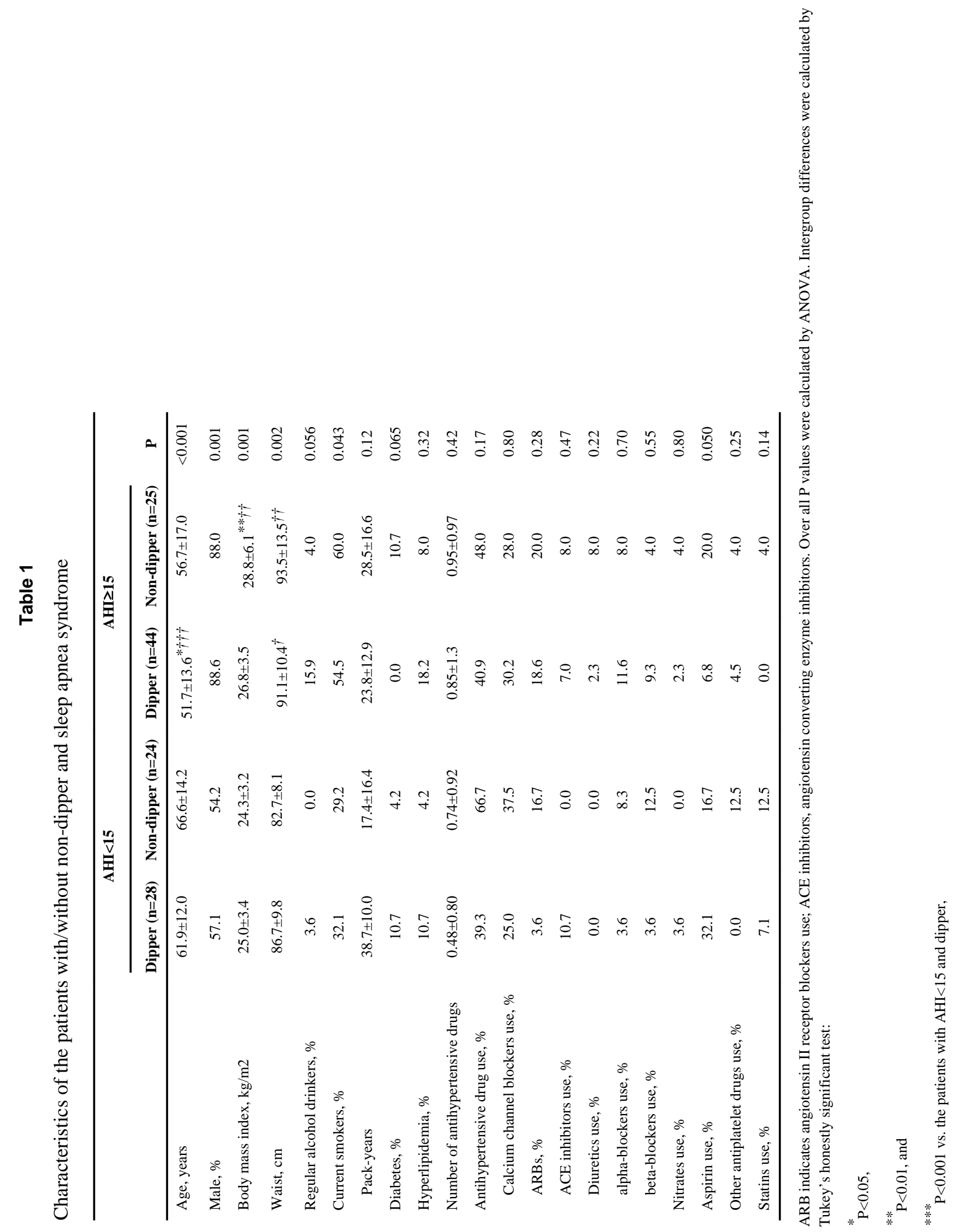




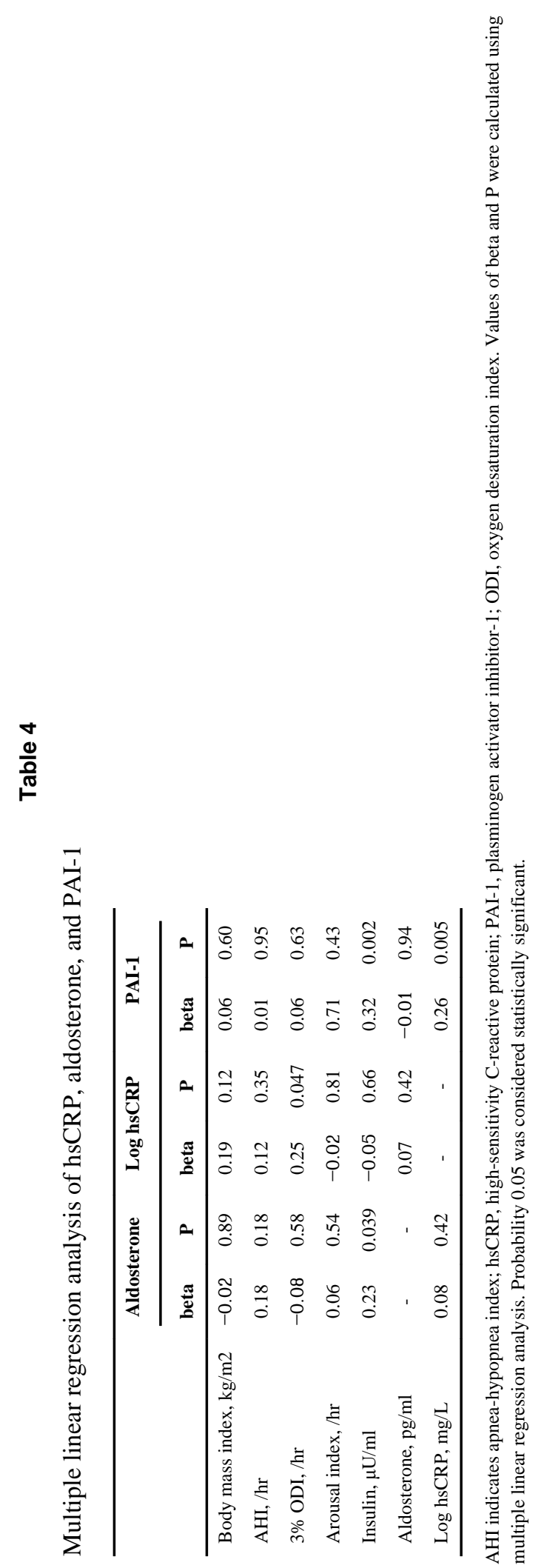

J Hypertens. Author manuscript; available in PMC 2011 March 30. 